\title{
Tirana, a History Through the Camera's Lens
}

\section{Lira Çaushi}

Assoc.Prof.PhD., Tirana University, Tirana, Albania isulo2000@yahoo.com

\section{Doi:10.5901/mjss.2014.v5n3p654}

\section{Abstract}

Photography comprises a particular technical social activity but simultaneously is one of the visual arts most spread in the world. On the technical aspect, it preceded the birth of cinematography "the reproduction art of motions", and later of television. Tirana's history through photography includes many social aspects of life like history, science and education, culture, publicity, security, crime, sport, documentation, friend and family nostalgic memories. Photography inclusion in this study gave a push to a more in-depth and fundamental research in the archives of the Republic of Albania, in the published albums of local and foreign photographers in order to select the most aesthetically achieved photos. The study of Tirana through photography of the previous years has enabled hence the title "Tirana, a history through the camera's lens" because after every frame the public finds images that are suited to such a title". Images in the focus of the camera bear problems related to downtown urban areas of Tirana that began in the 17th and 18th century. Today, the social complex of Suleiman Pasha Ballgjini is accepted as the artistic representation of this period, made up of a mosque and madras, a minaret and a public bath supplied with water from a fountain into the mosque. In photo frames there is also the center of Tirana, a monumental ensemble that started to be built in the years 1929-1930-1931, conceived by the Italian architects Armando Brasini and Florestano de Fausto. The center of this museum area was enriched with genuine national values like the symbols of Alexander the Great and Scanderbeg. Scanderbeg square became through years a proper square in the history of the city and of the country. The archeological and historical values of Tirana are based on the fact that it unified in harmony the existing values of this town with the new ones that Tirana was achieving as the capital city of the country.

Keywords: photo, image, event, archeology, urban center, experience.

The Traces of the near and distant past of a country can be explored in many ways, through the sources of written documents, and those of different forms and contents.

In order to know the past of our capital I will use pictures taken during the times when Tirana was like a new born child up to when it grew up and matured, competing with how it looked and what it stood for with the prestigious regional capitals, which although are more ancient, do not cause the jealousy of anyone, less so ours who have the pleasure to live in here.

In this journey in time, I will try to be as much as possible precise, experiencing the most critical moments during which Tirana was captured in pictures, focusing mainly in its early years as a town, and later as a capital.

At a first it looks as if choosing Tirana as a capital was a matter of luck, compared with other pretending towns like Durres, Korca, Vlora, Shkodra, Elbasan, and so forth. But the reality is a different one. The same as the other towns, Tirana likewise has its own history of birth and development, with its impact of being on the cross-road between north and south of the country and being nearby Via Egnatia.
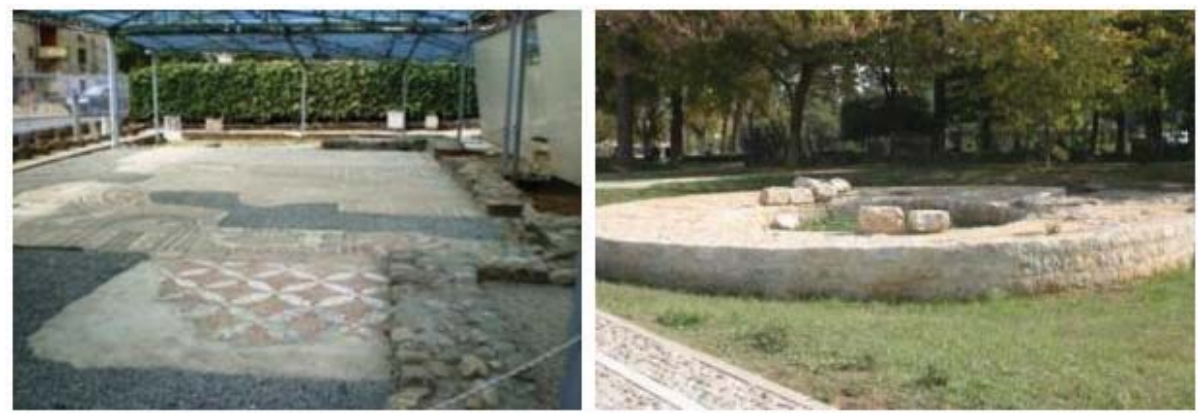
From the first century of our era there were settlements with different names in Tirana. Although the name of the town will be documented for the first time in the Venetian document of the $15^{\text {th }}$ century (1418), Tirana was inhabited since the first centuries of our era. This will be proved from the well known Mosaic of Tirana, at the beginning of the $3^{\text {rd }}$ century AD, which is a trace of a house and then the floor of an early paleo-Christian church.

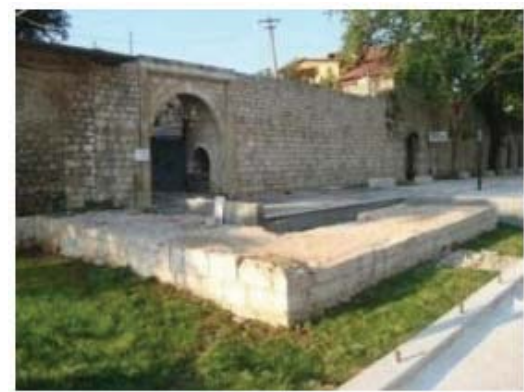

Of the same period is also the castle of Tirana, a station on the Via Egnatia. This castle was supposedly known by the $6^{\text {th }}$ century under the name of 'Tirkan'.

The castle, one of the most ancient evidences of the town, is located exactly on the spot where once met the roads going all over Albania. Such castles are also found on strategic locations of other roads, serving for protection and control of trading transport.

In the writings of Marin Barleti, in the $15^{\text {th }}$ century, Tirana is presented as a settlement divided in Large Tirana (Tirana e Madhe) and Small Tirana (Tirana e Vogël). In this century there were 1000 houses and 7300 inhabitants, while a century later these figures go up to 2900 houses and 20.000 inhabitants. ${ }^{1}$

Despite that, Tirana acquires its full features of a settlement with its own cult institutions and bazaar only at the beginning of the $17^{\text {th }}$ century. Starting from this century i think Tirana has 5 development's phases, which are connected to the five most important periods in the history of Tirana.

At the beginning of the $17^{\text {th }}$ the two buildings, built in 1614 , a mosque and a hamam (the Mosque of Suleyman pasha, today the Monument of Unknown soldier) made up the nucleus of Tirana. ${ }^{2}$
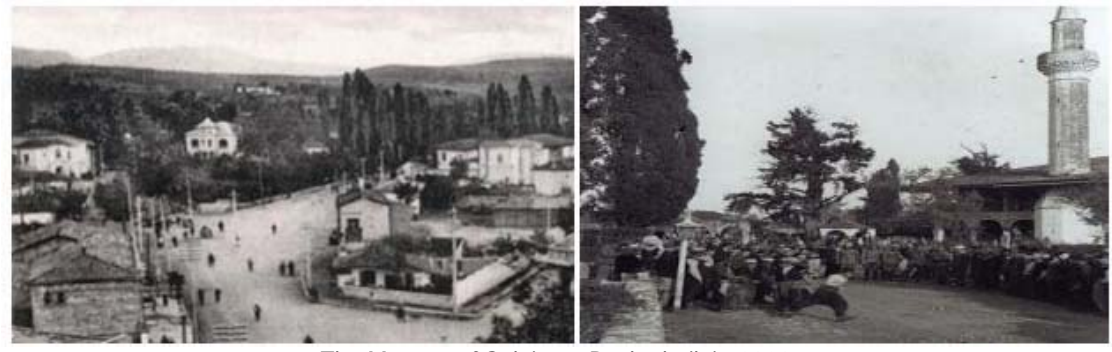

The Mosque of Suleiman Pasha built in 1614

The mosque was a simple one, but with an important combination of architectural elements and local technology. ${ }^{3}$

The area around the mosque and fortress formed and the old city core. Later on Tirana comes up with two old neighborhoods, that of Mujo and of Bazaar, ${ }^{4}$ which were located in the area that corresponds to Tirana's today town centre and Elbasani Street, on the side of Lana river.

\footnotetext{
${ }^{1}$ From the land census of 1431-1432 by the Ottoman administration it results that Tirana had 1000houses and 7300 inhabitants, from the census of 1583 in the region of Tirana there were 2900 houses and 20.000 inhabitants. In 1703 there were 4000 inhabitants, in 1820 there were 12.000 inhabitants, in 1838 there were 38.000 inhabitants, while in 1901there were 15.000 inhabitants. In the beginning of the 20th century there were 700 shops in Tirana and after the liberation in 1945, Tirana had 60.000 inhabitants.

2 These buildings were build by Suleyman Pasha in 1614. His family originated from Mulleti.

31.Demneri, Sh. Rreli, Tirana dhe Tiranasit kane vlera te pamohushme. Tiranë 2009, fq. 19.

4 This is two centuries later, when in Tirana the most important family was that of Toptani.
} 

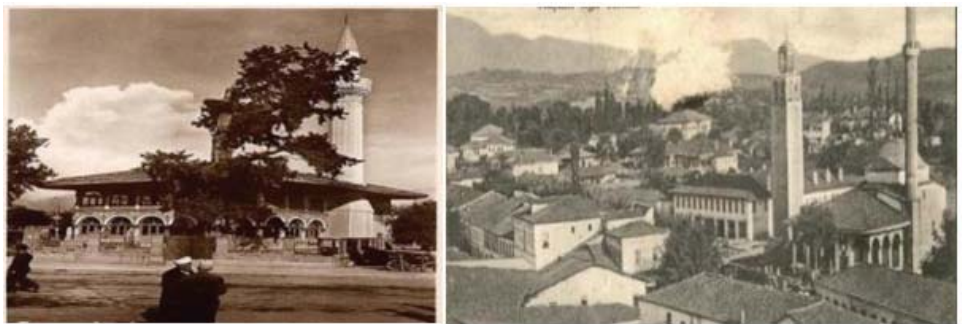

The main constructions in Tirana, in 17-18 centuries, were primarily places of worship, markets and small residential homes. Cult objects are added in 1780 to Tirana, as the Church of St. Prokopius and, a few years later (1789), at the center of Tirana, Molla Bey starts by building a mosque which is known today as the Ethem Bey Mosque, completed by the Haji Ethem Bey, the grandson of Sulejman Pasha. The mosque is typical of the Ottoman period. The external structure is stone, with a large porch, characteristic feature of countries with Mediterranean climate. The mosque is decorated in all its insides and especially in the porch with interesting frescoes.

Within a short period, circa 1821-1822, started the construction of the clock tower. Its completion added to the centre two other objects of high artistic value contributing to the multiplying of the capitals sightseeing. Clock Tower wins again the attention in 1928. It was reconstructed, adding to it another 6 meter high construction, reaching so the height of 35 meters. That same year was also bought in German the tower's Clock, which was placed on it. ${ }^{5}$
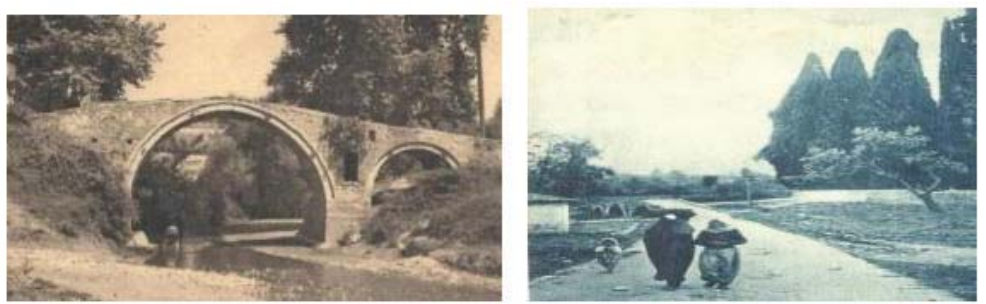

Within this same period (1865) was built St. Mary's Catholic Church, which was funded by the Austro- Hungarian Emperor, Franz Joseph, the Bridge of Tabak, ${ }^{6}$ the Bridge of Terzinjve, the latter is located near today's Elbasani Street Brigde. The construction of these bridges was financed by the respective esnafs (guilds). Bridges were raised with the respective guild funding.

With the time Tirana attracted the attention of the traders, artisans and of the inhabitants around. This contributed to the growth of the population and of the private houses.
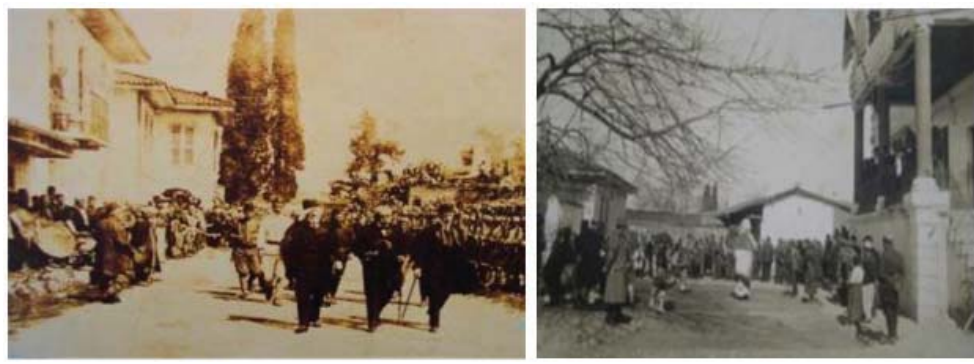

${ }^{5}$ In 1928 the Clock Tower was raised to the heights of 35 meters, and a modern German Clock for the Tower was bought by the Albanian government. The clock Tower was damaged during the WWII and was reactivated on July 1946.

${ }^{6}$ The bridge was named so because it was constructed at the neighbourhood of Tabakhane, which was itself named after the guild of Tabak (esnaf) who played a key role in the social and economic life of Tirana during the 17th and 18th century. The bridge with the same name connected two side of the Lana River, and was $n$ evidence for the enlargement of the town and of the communication with the surroundings. The importance of the bridge would decreased when Lana River changed its direction. 
With the proclamation of Tirana as provisional capital by the Congress of Lushnja in 1920, Tirana had a population of inhabitants, also it had many hotels, well-constructed houses, a big market for the town and lots of religious buildings, all constructed according to the architectonic style of the time.

The Government that came out from the Congress of Lushnja, headed by Sulejman Bey Delvina, made its residence in Tirana in 11 February 1920, welcomed warmly by the local population.?

De facto Tirana was proclaimed as capital of Albania in 1920, but de jure this was realized after five years in 1925 after a decision taken by the Albanian parliament. From this moment became a social and political centre of a great importance.

In its beginning the government took residence in private houses an in the building in the service of the army. The first three governmental buildings, of typical local Tirana architecture, are located next to each other. In the first building resided the parliament and the Foreign Ministry, in the second the Prime Ministry, and in the third the Ministry of Justice. These building were presumably located there where today is the Street of Elbasani.

When the government took residence in Tirana in 1922 it started the first regulatory plan of the town drafted by Albanian architects, a plan that was to be followed by others drafted mainly by foreign architects. The plan of 1922 marks the beginning of the second transformation of Tirana from a town into a capital.

The first plan foresaw the construction of the market and the areas occupied until then by the cemetery around the religious buildings. According to the plan, was constructed the Street of Durrës, with the purpose of creating an open view from far of the city. This street was named Nëna Mbretneshë.

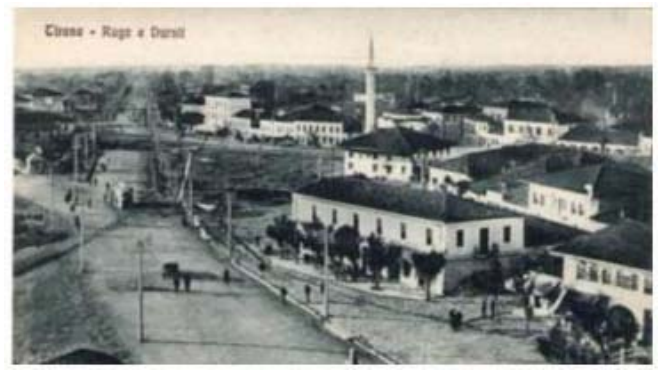

At the end of this street on the direction from Tirana to Durrës during the 1930-ies was foreseen by the Italians the construction of a depot, which was the starting point of the airport construction. The depot was constructed at the area were today is located the Sport Palace.

Tirana's architectures did not think only about roads, but also about different social and cultural centers. In 1922 was founded the National Museum, where the first archaeological collections were gathered (the museum was shut down in 1925 by Ahmet Zogu) ${ }^{8}$. At the same time that the new roads and the enlargement of the existing ones were constructed by the municipality, in Tirana had started a new wave of private buildings.

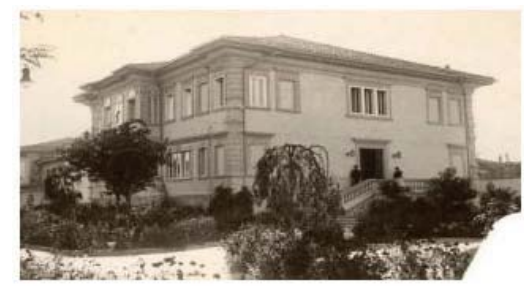

During the 1920ies was eracted the existing House of Parlament (1924), which was initially plannt as Officier Leisure Club. It was at this building that in 1928 Ahmet Zogu procailed the monarchy.

\footnotetext{
7 Tirana was proclaimed as a provisional capital of Albania on February 9 th 1920 at Congress of Lushnja. The members of the National Concil came to Tirana on February 11th 1920. Tirana was proclaimeddefinitive capital of Albania in 1925 by the Constitutional Assembly.

${ }^{8}$ Dom Mark Dushi, Tirana dhe rrethinat e saj, TOENA, Tiranë 2005, fq.13.
} 


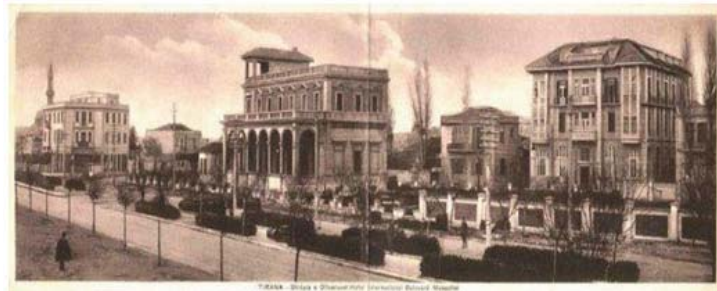

At the end of 1920-ies was opened for the first time the Royal Street (rruga mbretërore), today Rruga e Barrikadave, ${ }^{9}$ as well as the enlargement and the systematisation of Rruga e Kavajës ${ }^{10}$, that became the main artery of the capital. On the both sides of this street there were multi-storey buildings, their architectonical style was modern with neoclassical decorations.

The development of Tirana entered in its third phase. The capital's projects drafted by foreign studios, which took into consideration former projects, gave a new space and a new look to the capital.

With its new arteries, the city had a more effective communication with other parts of the country. The development and the perspective of the on the city brought about the building of the national bank on the crossroad of Rruga Kavajes and the main square.

The city grew up and with it its cultural life too. In 1926 the Beshiri brothers opened a cino-theatre, "Rex", later on named "Nacional", 11 known by our generation as cinema " 17 Nentori.

With its urban development Tirana was expanded into seven neighbourhoods, those of Abdulla Bej, Ismail Efendija, Lagjia e Re, Pazari, Sulejman Pasha and Xhamia e Sherifit. ${ }^{12}$
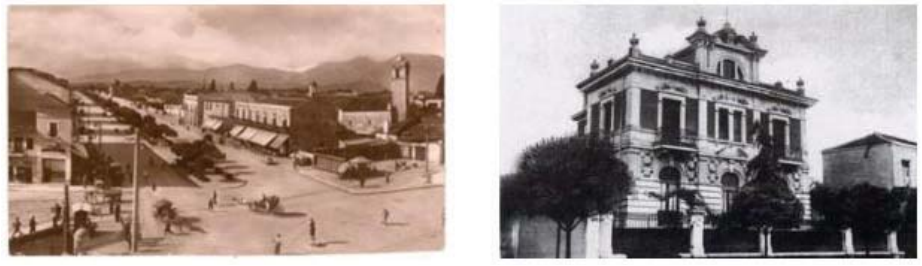

In 1930 the street known as 28 Nëntori was expanded, with it also the most important street of the town in Tirana today Zogu I Boulevard. This street started from Pasha Hill (Kodra e Pashës) today Scanderbeg Square up to Braka, today the Train Station. During these years, continued intensively the construction of private buildings, competing each other for their architectonical style. Even today these houses remain charming on the main street side of Tirana.

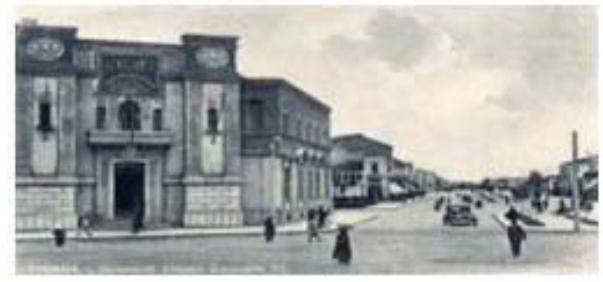

Also based on Italian project during 1929-1931, was constructed the new municipality building of the capital, ${ }^{13}$ together with six other buildings, which served as ministries. These buildings have their own neoclassical style. They are decorated with basso-relievo with the portrait of Scanderbeg, Lek Dukagjini and Pyrrhus of Epirus.

\footnotetext{
9 1926-1927

10 The Mussolini Boulevard expanded in the years 1928-1929; 1100 meters long and 30 meters wide.

${ }^{11}$ I.Demneri, Sh. Rreli, Tirana dhe Tiranasit kane vlera te pamohushme. Tiranë 2009, fq. 33.

${ }^{12}$ Dom Mark Dushi, Tirana dhe rrethinat e saj.TOENA, Tiranë 2005, fq.136

${ }^{13}$ The picture shows the Emanuel III Boulevard, today Zogu I Boulevard.
} 

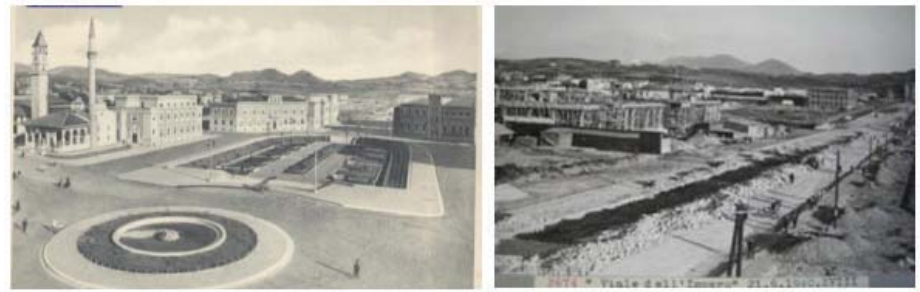

In the middle of these building during 1929-1931 was created a modern park for the period, projected to give a middle space between the two-story buildings around it. According to the written documents of the period there were 24.400 permanent inhabitants in the city and 11.693 commuters. The city extended on the surface of $8 \mathrm{~km}^{2}$, while in 1912 it was only $3 \mathrm{~km}^{2} .14$

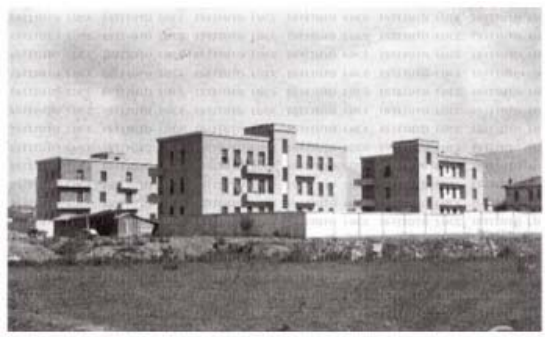

With the Italian occupation Tirana entered its fourth phase of urban development. During this period the works done in the centre of Tirana were in harmony and continuation with the former phases.

During the Italians occupation well-known Italian architects (Gherardo Bosio) worked again on Scanderbeg Square. There were few interventions to enlarge it and widen it. In this period came out for the first time the idea of demolishing of the municipality building in favour of the square's enlargement, which came to be realized during the Communist regime.

During the fourth phase on the southern part of Tirana started the works for the construction of the boulevard known today as Dëshmorët e Kombit. There were constructed a group of buildings, known today as Central Corpus of the University, the Rectorate, and the University of Arts. There were works where today is the Prime Ministry, were opened the foundation of the National Assembly offices, was build Hotel Dajti and Lana Bridge. There were projects for the construction of a stadium as well as the beginning of the construction of what is known today as Tirana e Re. The corpus was the extension of Tirana towards its south western part.
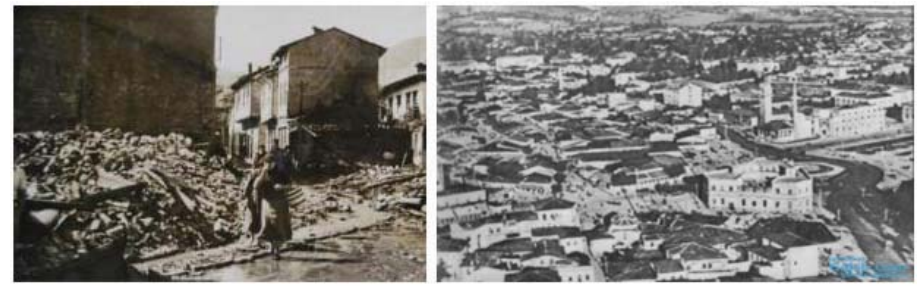

Views of Tirana before liberation in 1944

The continuation of these constructions was interrupted by the German occupation. In 1944 the same as the other cities, Tirana suffered a lot of damages, but luckily it center remained almost untouched.

In the first years after the liberation, in Tirana started the reparation of the damages suffered during the war. Although there were no new monumental important constructions, there were interventions on the pavement of the sidewalks. In the boulevard Dëshmorët e Kombit the works for the construction of Prime Ministry which started during the

${ }^{14}$ http://albakepiblog.wordpress.com 
1940-ies were finished. After 1945 was built on voluntary work the Rinia Park.

In the beginning of the 1950ies was finished the building of Central Committee, today the offices of parliament, which building started during the 1940ies.

After the 1950's, started the construction of the Pallatet Agimi, then, in 1957, the construction of Shallvare and Kinostudio the New Albania (Shqipëria e Re).

After these years the interventions in the main square of Tirana were accompanied with respective research. We may mention here the study for the Culture Palace, Grand Hotel, and National Museum, nine-stories building in the Barricade's Street, Palace of Congress, and that for the Pyramid. All these studies brought about in 1989 the draft of a new regulation plan for Tirana.

Staying conform to the development of phases of Tirana i would like to emphasize that as the years for the emergence solutions passed, we can divide the period after the 1960ies with in other subdivisions as regarding the urban development of the capital. Tirana grew not only in its main square, which was turned into a historical ensemble, but also around it.

Living the changes of Tirana after the 1960-ies for another study, i would say that Tirana today is part of European metropolis, whose daily progress is on contemporary basis. Tirana is a kind of city when far of it you miss every single street of it.

\section{Conclusions}

The story of the events and the authenticity of archival documents create a visual link. Especially today, when everything takes place rapidly, my interest in photography is to slow down the pace in dealing with my subjects. Thus, not only to create a story that enriches lives but also to keep their life experience. Any multicultural experience will be complex and multidimensional, it is as a kind of window into my experience as a researcher in the field of history.

Tirana history through the lens of photographers have significant impact on the identification of distinct creations with artistic value, things that are or will be published for an audience expanded from printing all the time, which is dynamically developing. The reflected images in this study, disclose a visual investigation into Albanian history and contemporary culture, reflecting individuals, landscapes and stuff which in my opinion, are an inseparable part of human existence as similar as they are different from that of my country.

Current historians use the normal parameters of photo technology as a means to unveiling artistic ideas and opinions. Plenty of local researchers and foreigners use photo images within their works, paintings, graphics and video, thanks to the miracle of photography, realized the veracity of historical events. Thus, the boundaries between photography and other media, day after day, are diluted, creating artistic works that arise numerous untested emotions to the viewer. In the field of traditional photography racing occurs between black and white pictures with color that also marks another race between technique and plated digital process. Time shows that despite the advantages of digitization, the plated picture will continue to exist with success. Also, many recent scholars are fanatics that picture are not affected by any kind of way as vehicles are shredded. But critics in a more specialized area believe that is more important to complete the artistic creative process, rather than the ways of, or simply put what remains to be seen in a photographic paper.

Today, almost every family has a camera with which the owner is trying to pull off beautiful pictures but also to replenish the family archive. The first is achieved with difficulty, while the latter carry values increased over time. For its specific characteristics, especially for reliability and comprehensibility, photography is a modern universal language.

\section{References}

Central Archives of the Republic of Albania (AQSH)

Demneri, I., Rreli, Sh., Tirana dhe Tiranasit kane vlera te pamohushme, Tiranë, 2009

Dushi, M. Dom., Tirana dhe rrethinat e saj, TOENA, Tiranë 2005

http://albakepiblog.wordpress.com 